\title{
Comparison of the Effect of Tetrapod Block and Armor X block on Reducing Wave Overtopping in Breakwaters
}

\author{
Omid Nourani1 ${ }^{1}$ Mehdi Behdarvandi Askar2* \\ ${ }^{1}$ Marine Structures, Faculty of Engineering, Islamic Azad University of Ahvaz, Ahvaz, Iran \\ ${ }^{2}$ Department of Offshore Structures, Faculty of Marine Engineering, Khorramshahr University of Marine Science and Technology, \\ Khorramshahr, Iran \\ Email: sazehenteghal@yahoo.com
}

How to cite this paper: Nourani, O. and Askar, M.B. (2017) Comparison of the Effect of Tetrapod Block and Armor Xbloc on Reducing Wave Ove Rtopping in Breakwaters. Open Journal of Marine Science, 7, 472-484.

https://doi.org/10.4236/ojms.2017.74033

Received: August 15, 2017

Accepted: September 26, 2017

Published: September 29, 2017

Copyright $\odot 2017$ by authors and Scientific Research Publishing Inc. This work is licensed under the Creative Commons Attribution International License (CC BY 4.0).

http://creativecommons.org/licenses/by/4.0/

(c) (i) Open Access

\begin{abstract}
As the Armor shape has a significant effect on the reduction of wave overtopping, this study compares the performance of various shapes of concrete armored blocks of $\mathrm{X}$ block and Tetrapod as the most suitable armors. In this study, a three-dimensional numerical model was used for simulation of the effects of waves on the armors of Tetrapod and X Block breakwaters. In this regard, in order to calibrate the numerical model, a sample of conventional stone armor has been selected and using available experimental data on the design of armor such as wave overtopping, wave height, period of waves and energy density of the required spectral range of wave verification was conducted on a numerical model. In this regard, it is necessary to calibrate all the conditions of the model including boundary conditions, numerical modeling, initial conditions, numerical solvers and other parameters in the numerical model and simulation error rate is determined. The maximum error of the numerical model for the relative height values of the impact waves on the structure of breakwater is $7.87 \%$ for different conditions. Accordingly, the maximum error of the numerical model in determining overtopping values is $7.81 \%$. The average fluctuation value of overtopping in the $\mathrm{X}$ block armor has dropped by about $31 \%$ compared to the tetrapod armor.
\end{abstract}

\section{Keywords}

Wave Overtopping, Numerical Model, Tetrapod, X Block, Flow3D 10.1, Wave Collision

\section{Introduction}

The overtopping of waves from coastal structures is one of the most important 
hydraulic reactions considered in the design of these structures. The phenomenon of wave overtopping, especially regarding the protection structures of cities and installations, such as coastal walls and dykes is important because overtopping through these structures can lead to structural damage and loss of life or financial losses. As shown in the figure below, wave-overtopping processes is the collision of the wave to structure, upstream, and eventually overflow of water from the structure [1] [2]. This phenomenon has caused many damages in coastal structures and their existing structures in the past and present. Due to the uncertainty in predicting the level of water design, as well as in determining the design waves on the one hand, and on the other hand, in terms of economic cost, the construction of high structures, accepting the occurrence of overtopping is unavoidable [3].

A lot of research has been done on the phenomenon of wave overtopping of coastal structures in the last 50 years. These studies have led to continuous corrections in overtopping prediction methods from shore protection structures and deformation of various armored vehicles against sea waves [4]. Existing methods are divided into two groups of numerical and experimental methods. In recent years, in spite of more affinities with the nature of the phenomenon, due to the high cost of testing the equipment and the difficulty of creating a situation similar to that of the nature, laboratory methods have been used less commonly. However, in numerical methods despite their complexity, due to different perspectives were carried out after the study of the research and the knowledge available on the phenomenon of the overtopping of waves from coastal structures with an analytical look at the strengths and weaknesses of existing models, the failure modeling and wave overtopping modeling, they have focused on coastal structures and attempts to focus on studies that take into account the more details of the phenomenon.

Generally, for a given storm, the total volume of water overtopping is generally predicted by the methods of Jensen and Van in Mayer (1994), Owen (1980), Hudges and Reis (1998), which are based on empirical experiments [5] [6] [7]. However, Godda (2000) has shown that these formulas do not totally cover the complexity of waves in shallow water and may largely predict overtopping fluxes below actual values [8]. Analysis by Bessley et al. (1998) also shows that methods that do not take this effect may predict the overtopping through underlying waves below actual values [9]. This finding has been supported and confirmed by numerical studies by Hugh et al. (2000) [10]. With the increasing computing power of computers, numerous computational models have been developed to model wave overtopping of structures in recent years. Kubayayashi and Vorjantou, who dealt with numerical modeling of regular wave overtopping of offshore penetration structures on a sloping coast, undertook the first serious attempts in this area in 1989 [10]. Marviyama and Hirashi (1998) presented a numerical model for calculating overtopping flux of the multi-directional waves from a vertical breakwater [11]. The basic assumption of this model was that overtop- 
ping flux could be defined by an overflow relationship. A two-dimensional numerical model for calculating the transition from shallow water nonlinear equations, but this study is valid only for regular waves. For the purpose of 3D modeling and calculation of overtopping discharge from irregular waves, methods were used that were based on fluid volume. The success of these methods is to study the overtopping process with more detail than is possible in physical model experiments.

Considering that Tetrapod and X Block armors have a wide application in different countries, in this study, using numerical 3D modeling, after the calibration and verification steps, the results of the relative flow velocity values for overtopping these two armors have been studied and their results can be used in the design of such armors.

\section{Materials and Methods}

In this study, using Flow3D numerical model, three-dimensional overtopping waves were simulated on the tetrapod and $\mathrm{x}$-block armors. This software has been developed by Flow Science. The software is based on the complete solution of Navier-Stokes equations. This software solves the Navier-Stokes equations using a finite difference method [12]. With the increasing application of this software by companies and research institutes, it can be stated that the software is capable of modeling complex hydraulic, hydrodynamic and so on issues, especially free-area issues. Evidence of this is the growing number of articles in which the software has been used. Accordingly, using a geometric and hydrodynamic condition of an existing experimental model of breakwater of a numerical model is constructed for this study. Then, using the created model, different geometric and hydraulic conditions can be applied to the present model and the results of the model are extracted and analyzed [13]. Data analysis will be examined using other studies that have been carried out on these structures [14]. It should be noted that the numerical model presented in this study provides necessary information for the velocity, pressure, and depth values for different transverse and longitudinal sections that can be analyzed using the outputs of the model. Moreover, the present numerical model has the ability to determine overtopping discharge rates over time.

\section{Numerical Simulation Method in Flow3D Numerical Model}

To specify the networking boundaries, those blocks are specified in which all dimensions of the structure and the free space within it is defined. In the figure below, the rigid geometry made by SolidWork software has been added to the Flow3D numerical model and constructed using grid and computational blocks to determine the overtopping discharge rate of the breakwaters in the Flow3D numerical model (Figure 1 and Figure 2).

The block is exactly in accordance with the requirements of the laboratory model, and in order to calibrate and validate the model, such conditions must be 




Figure 1. Construction and design of three-dimensional geometry of concrete tetrapod blocks in breakwater coating.



Figure 2. Construction and design of three-dimensional geometry of concrete $\mathrm{X}$ block armor in breakwater coating.

applied to the numerical model. This block has dynamic grids, and in other words, it is located at the cross section of a smaller grid, and in other areas with larger computational cells (Figure 5). Using the Dynamic Grid Block in this model, the accuracy of calculations in the region focusing on the cross section of the wavelet has increased. A smaller grid area has been adapted to the geometry of the breakwater with a stone armor.

\section{Calibration and Numerical Model Verification}

In order to calibrate and validate the numerical model of laboratory studies of Bruce et al. (2008) have been used. In this study, a jumper flame with irregular waves with the Jonswap spectrum hits the crustal section and the flow rates are measured using laboratory equipment. Therefore, in this section, we try to extract the overtopping discharge values on a section of the crater with a stone armor from the numerical model by simulating the precisely experimental conditions and calculating the error of the Flow3D numerical model in this field [15]. Then, by changing the different armor and numerical geometry of the numerical model, the parameters for reducing the overtopping flow velocity in the breakwaters will be investigated. It should be noted that the waves are irregularly produced with the Jonswap spectrum, and the maximum wave height is $12 \mathrm{~cm}$ high and with a period of 1 second to the breakwater section [16]. In laboratory studies, with the installation of discharge gauges in line at the end of the labora- 
tory model, the discharge rate due to overtopping of waves has been measured. In the numerical model, using the output boundary profile, we can extract the flowing wave velocity from a breakwater with a stone armor. After various modeling according to different conditions, the results of the numerical model are compared and evaluated based on the best conditions for modeling the results of the numerical model with the experimental results. Calibration and verification of the results of the numerical model are divided into two parts. The first part for the calibration and verification of the numerical model for hydrodynamic parameters of the model includes periodic values, wave height, and maximum values of the energy spectrum and its comparison with laboratory values that will be done to determine the precision of the numerical error in simulating the hydrodynamic parameters. The second part will be based on the parameter of overtopping flow rate and the accuracy of the numerical model.

The following figure shows a three-dimensional wave encounter is a wave-to-break collision under the conditions of a first run of waves at an altitude of $11 \mathrm{~cm}$ and a period of 1 second, while in the second run, the waves rise at 10 $\mathrm{cm}$ and a period of 2 seconds according to the conditions.

In the following Figure 3 and Figure 4, the energy spectrum of the energy density of the impact of waves on the crushers' structure is extracted from the numerical model and evaluated with the wavelength energy density spectrum in laboratory mode (Figure 6).

In the Table 1, the values of the wavelength, period and maximum density of the wave spectrum for two states of the generated waves in the Flow3D numerical model are calibrated and verified. In the table below, the relative error values of the following equation are used:

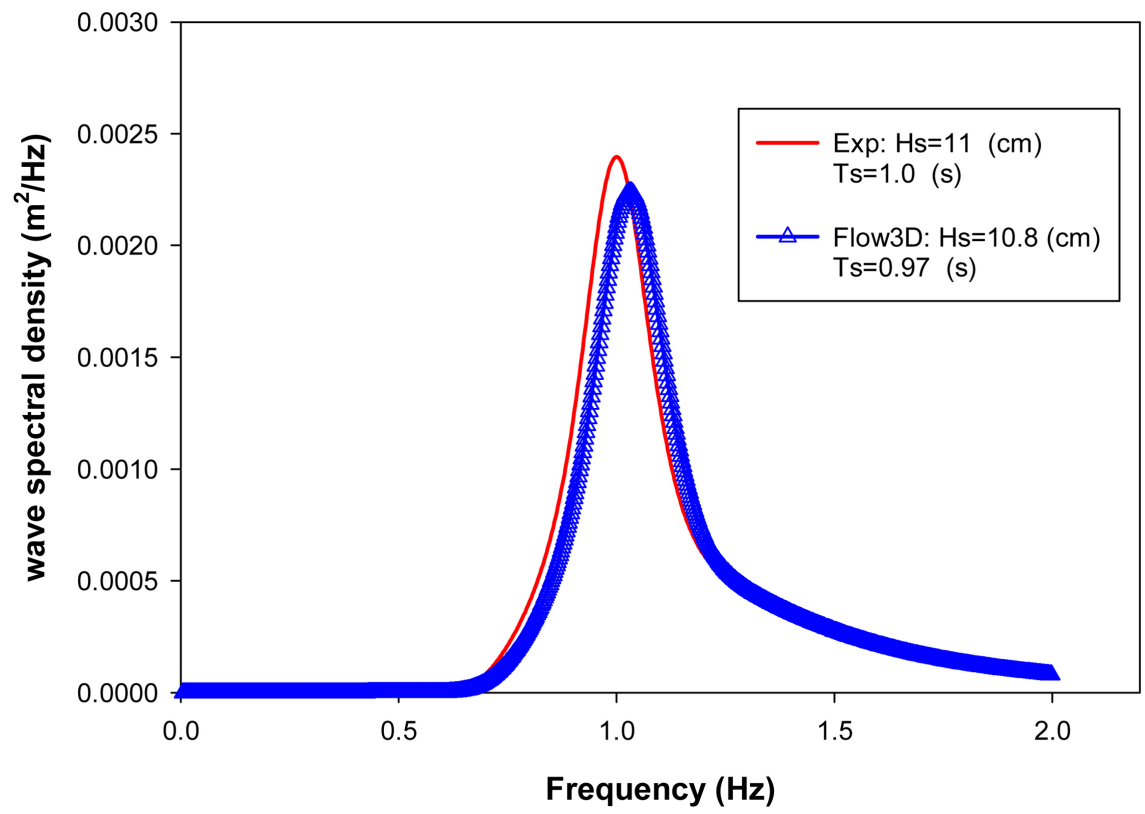

Figure 3. Comparison of wave energy spectrum density in Flow3d laboratory and numerical modeling. 




Figure 4. Comparison of wave energy spectrum density in Flow3D laboratory and numerical modeling.

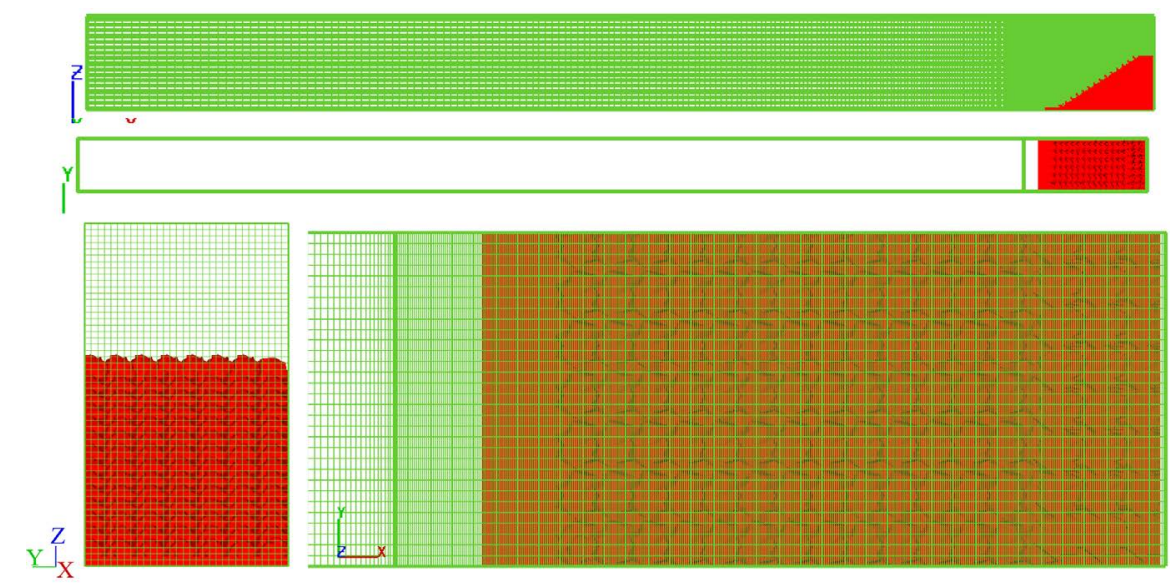

Figure 5. Different views of grid block and smaller computational cells in the breakwater cross-section.

$$
\text { Error } \%=100 * \frac{X_{E x p}-X_{N u m}}{X_{E x p}}
$$

In the above relationship, XP is the actual value of the parameter (lab values), and $\mathrm{XM}$ is the simulated value of the desired parameter.

As shown in the Table 2 above, the hydrodynamic simulation of the wave propagation model from a breakwater with a rocker armor for wave height, wavelength period and peak density of simulated wavelength spectra are very close to laboratory conditions. Based on the results of numerical modeling, the maximum relative error of the numerical model in the height and period parameters of the waves are respectively 4.5 and 3 percent. In addition, the maximum error 


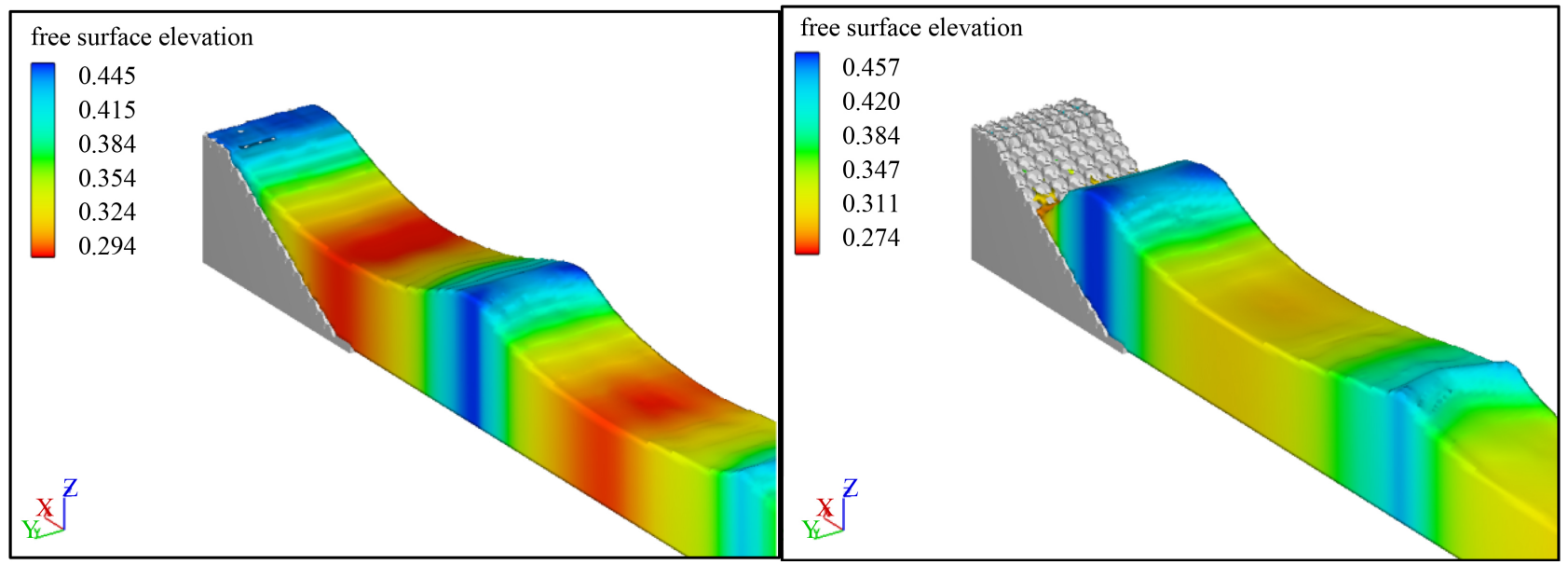

Figure 6. The collision of waves in a breakwater section with stone armor for calibration and verification of Flow3D numerical model.

Table 1. Comparison of validation and calibration results of a numerical model for hydrodynamic parameters of the Flow3D numerical model.

\begin{tabular}{ccccccc}
\hline \multirow{2}{*}{ No. } & \multicolumn{3}{c}{ Experimental } & \multicolumn{3}{c}{ Numerical } \\
\cline { 2 - 7 } & Hs $(\mathrm{cm})$ & Ts $(\mathbf{s})$ & S(f): $\mathbf{m a x}$ & Hs $(\mathrm{cm})$ & Ts $(\mathbf{s})$ & S(f): $\mathbf{m a x}$ \\
\hline Run 1 & 11 & 1 & 0.00241 & 10.8 & 0.97 & 0.00227 \\
Run 2 & 10 & 2 & 0.00396 & 10.54 & 1.98 & 0.00422 \\
& & Run 1 & & & Run 2 & \\
Error \% & 1.81 & 3 & 7.88 & 5.40 & 1 & 6.56 \\
& & & & & & \\
\hline
\end{tabular}

Table 2. Comparison of validation and calibration results of a numerical model for parameters of relative wavelengths and overtopping flow in a Flow3D numerical model.

\begin{tabular}{|c|c|c|c|c|c|c|}
\hline \multirow[t]{2}{*}{ Run No. } & $\begin{array}{l}\frac{R_{c}}{H_{m 0}} \\
\operatorname{Exp}\end{array}$ & $\begin{array}{c}\frac{R_{c}}{H_{m 0}} \\
\text { Num }\end{array}$ & \multirow[t]{2}{*}{ Error \% } & $\begin{array}{c}\frac{q}{\sqrt{g H_{m 0}^{3}}} \\
\operatorname{Exp}\end{array}$ & $\begin{array}{c}\frac{q}{\sqrt{g H_{m 0}^{3}}} \\
\text { Num }\end{array}$ & \multirow[t]{2}{*}{ Error \% } \\
\hline & \multicolumn{2}{|c|}{ Run 1} & & \multicolumn{2}{|c|}{ Run 2} & \\
\hline Run No.1 & 0.78 & 0.72 & 7.69 & $1.5 \times 10^{-3}$ & $1.41 \times 10^{-3}$ & 6.10 \\
\hline Run No.2 & 1.15 & 1.07 & 6.95 & $6.0 \times 10^{-4}$ & $5.7 \times 10^{-4}$ & 5.00 \\
\hline Run No.3 & 1.2 & 1.17 & 2.5 & $8.0 \times 10^{-5}$ & $7.8 \times 10^{-5}$ & 2.50 \\
\hline Run No.4 & 1.45 & 1.37 & 5.51 & $4.0 \times 10^{-5}$ & $3.7 \times 10^{-5}$ & 7.52 \\
\hline Run No.5 & 1.65 & 1.52 & 7.87 & $1.65 \times 10^{-6}$ & $1.52 \times 10^{-6}$ & 7.81 \\
\hline
\end{tabular}

of the simulation of the peak density values of the energy spectrum of the waves versus the experimental results is $88.8 \%$. Comparison of the values of the results of the hydrodynamic parameters and their relative error indicates that the present numerical model has acceptable relative error values, and the numerical simulation of the hydrodynamic parameters is a calibrated and verified model. In order to calibrate and verify the overtopping discharge, values in different conditions of the waves in a breakwater with stone reinforcements and the 
available experimental results are evaluated in the studies of Bruce et al. (2008). One of the most important relationships for determining the amount of the discharge of overtopping of the waves of breakwaters that considers the most important geometric and hydrodynamic parameters of the plan is given by TAW, 2002 as follows:

$$
\frac{q}{\sqrt{g H_{m 0}^{3}}}=0.2 \exp \left(-2.6 \frac{R_{c}}{H_{m 0}} \frac{1}{\gamma_{f}}\right)
$$

In this equation, $q$ is the values overtopping discharge of breakwater in unit width, $H_{m 0}$ is the wave height of the indicator, $R_{c}$ is the free height of the breakerwater, $\gamma_{f}$ is the coefficient of roughness of the materials, which are given in different references for each armor. It should be noted that the parameter $\frac{q}{\sqrt{g H_{m 0}^{3}}}$ is a dimensionless parameter. In the present study, we have tried to use numerical results and experimental results to validate the numerical model. In the table below, two sections of numerical and laboratory results and simulation error rates are presented. In the table below, the values of the relative error between the experimental results and the results of the Flow3D numerical model are extracted and calculated for the same conditions. Comparison of the parameter of the post-discharge flow rate after overtopping rocky armor with different wave and period conditions are investigated. It should be noted that various tests have been performed with boundary conditions, initial conditions and network conditions in a numerical model, and the best results of the numerical model are presented in this section.

As shown in the table above, the maximum error of the numerical model for the relative height values of the collision waves to the crusher structure is $7.87 \%$ for different conditions. Accordingly, the maximum errors of the numerical model in determining the fluctuating flow rates relative to the laboratory conditions are also $7.18 \%$. It should be noted that the results of the above table have been obtained by different tests and checking available parameters. Therefore, the present numerical model can be calibrated and verified, and can be compared with similar conditions for simulation of collisions waves to breakwaters with other curtains.

In the diagram below, the relative overtopping flux changes $\left(\frac{q}{\sqrt{g H_{m 0}^{3}}}\right)$ are plotted against a rocker armor relative to the relative height $\left(R_{c} / H_{m 0}\right)$ in two laboratory and numerical modes.

\section{Discussion and Results}

As shown in Figures 7-10 the different sections of the present study, one of the most important parameters affecting the climbing and passing of waves on the structure of crushers is the geometric shape of the stone and concrete reinforcements. Therefore, based on the research objectives in this section, the study of 


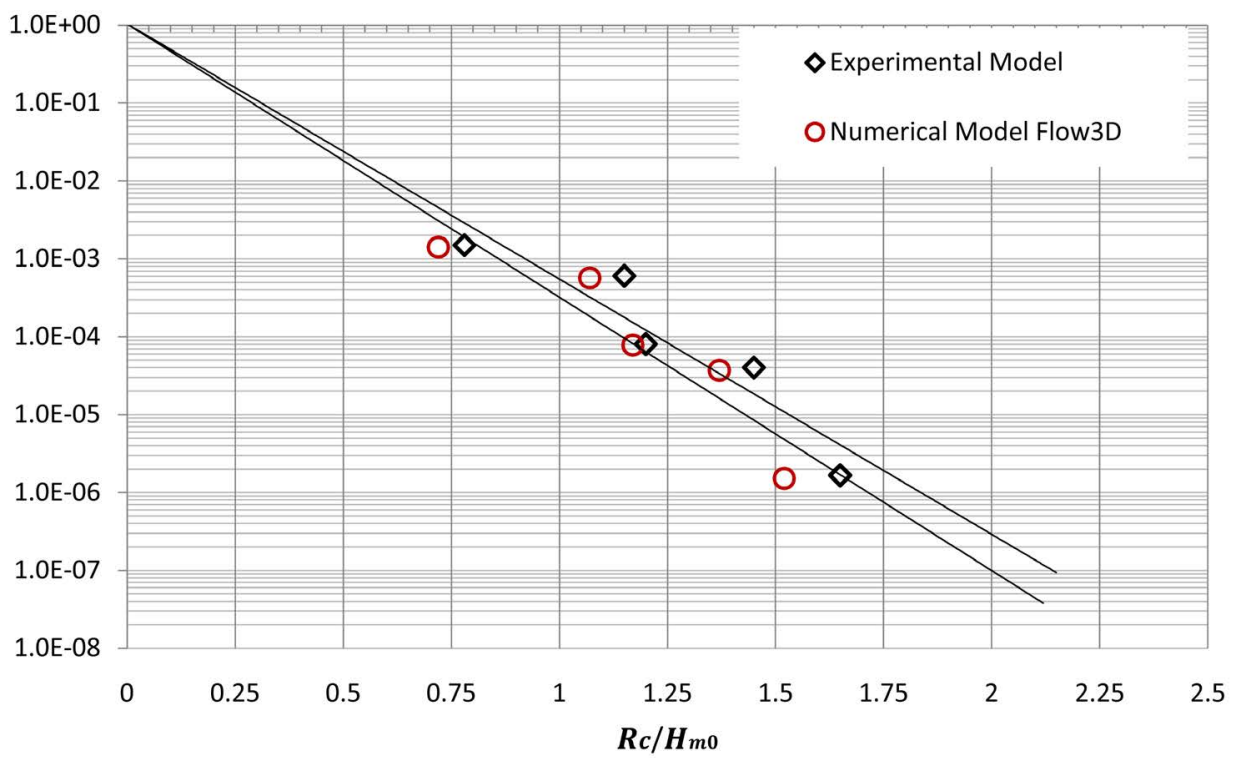

Figure 7. Changes in relative overtopping flow rate $\frac{q}{\sqrt{g H_{m 0}^{3}}}$ from a rocket armor against a relative height $R_{c} / H_{m 0}$ in two laboratory and numerical modes.

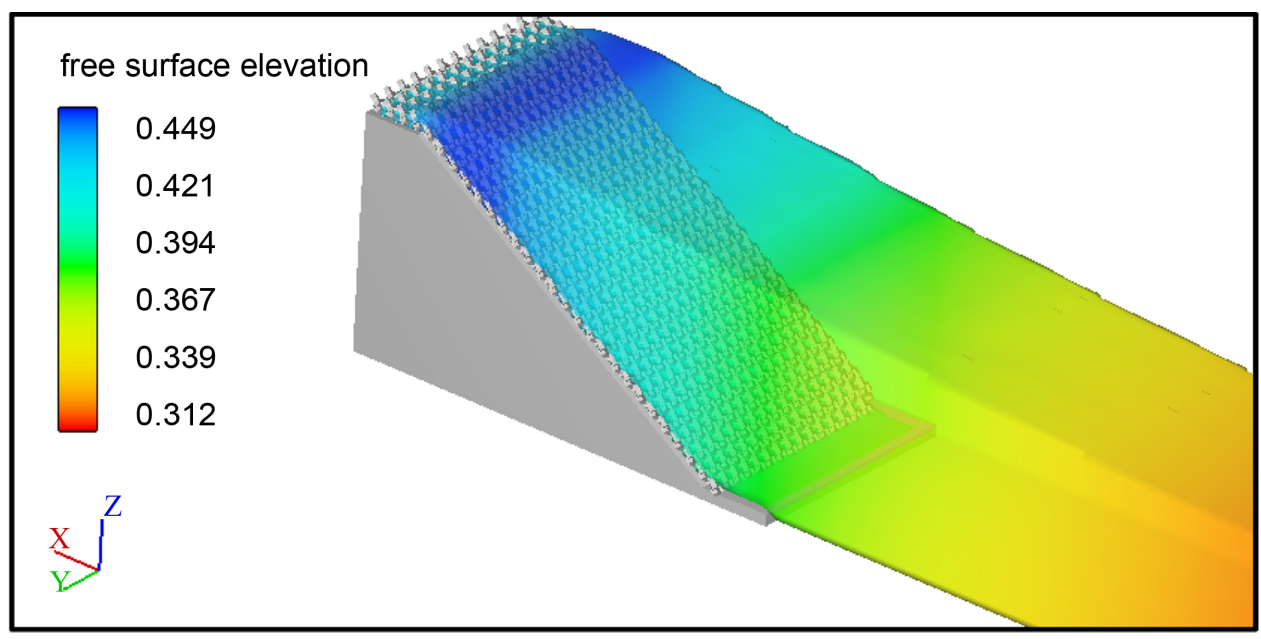

Figure 8. The quality of pass of overtopping through the X-block armor from the breakwaters.

the amount of flux discharge values for the X-block armor and the concrete blocks of the tetrapod is evaluated. The numerical model is simulated using different wave height conditions. The results of the discharge outlet of the breakwater with the tetrapod and X-block armors for 300 seconds are given as follows. It should be noted that given the fact that in the model, the amount of discharge per unit of time for the model can be measured, finally, for the evaluation of the numerical model, the mean of the output of the model must be measured. The results of the Flow3D numerical model are derived in the graphs below, based on 0.5 second intervals.

In the first step, numerical modeling for $\mathrm{x}$-blocks is done. Accordingly, using the geometry of the X-blocks in the previous section, the condition of 5 different 


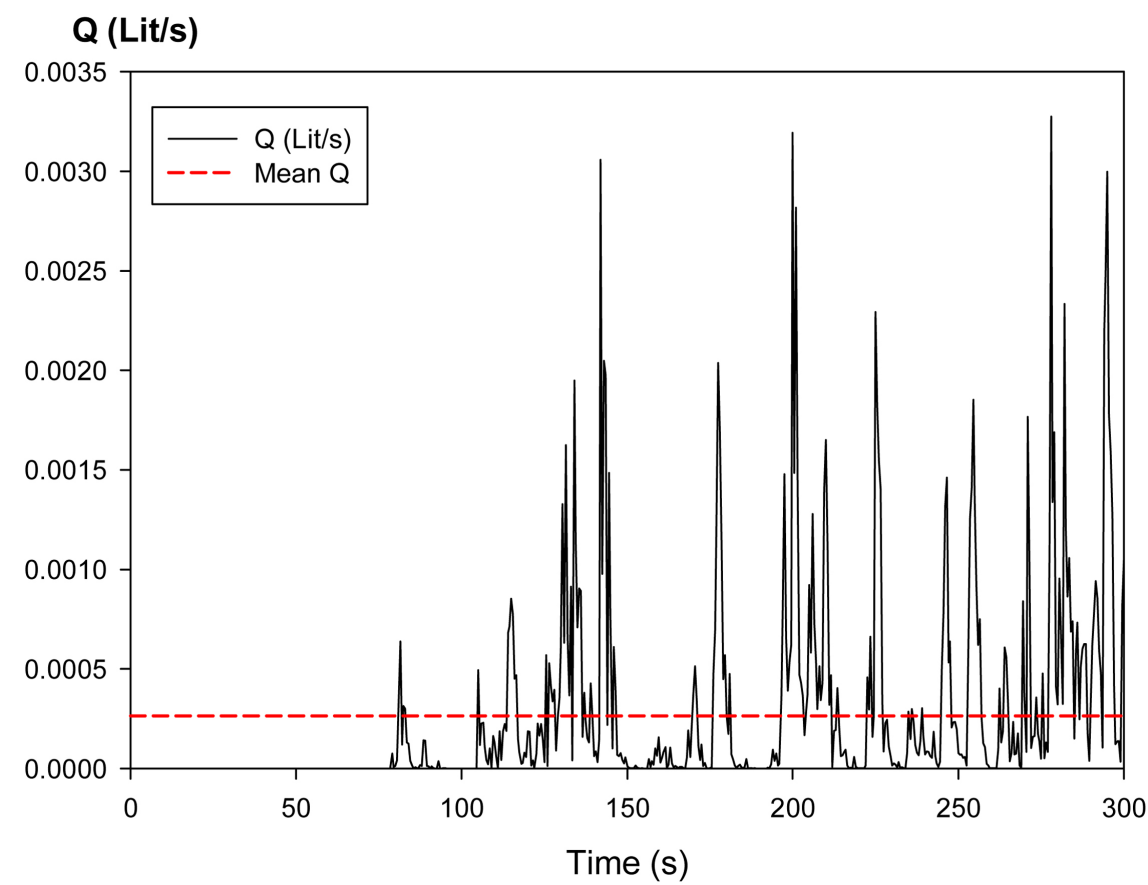

Figure 9. Output flow variation diagram in terms of time and average rate of discharge output from armor X Block breakers.

waveforms with different height and period that has a flow passage on the Armor X Block has been applied. After the extraction of the numerical results, the transmitted overtopping rates for the maximum wave height were extracted during the simulation period from the numerical model. In the following figures, the form for how the flow of discharge changes based on the time and the $3 \mathrm{D}$ view of numerical modeling is shown.

In step five, numerical modeling for the tetrapod blocks is one of the oldest and most practical coatings for breakwaters. Accordingly, using the geometry of the tetrapod blocks constructed in the previous section, 5 different waveforms with different altitudes and periods with flow overflow on Tetrapod armor have been applied. After extraction of the numerical results, the transmitted overtopping rates for the maximum wave height were extracted during the simulation period from the numerical model. The following figure shows the flow of discharge changes based on time and three dimensional numerical modeling in the figure below.

In the Table 3 above, the flux overtopping values for the two most commonly used armor breakwaters are derived from the Flow3D numerical model. In order to compare, different models of armor, tetrapod, X-block, and stone armor are plotted below. In this chart, the fluctuation of overtopping has been plotted relative to the relative altitude of the waves.

As seen in the Figure 11, the relative overtopping flux values for different armor have different values. According to the results of the numerical model, the armored vehicles have the lowest amount of overtopping in similar conditions to other concrete blocks of the block, Haro Block and Tetrapad. 


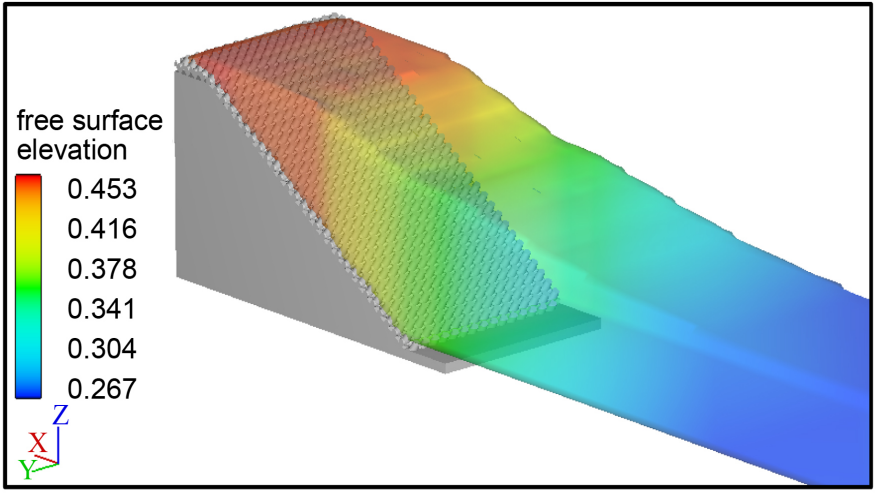

Q (Lit/s)

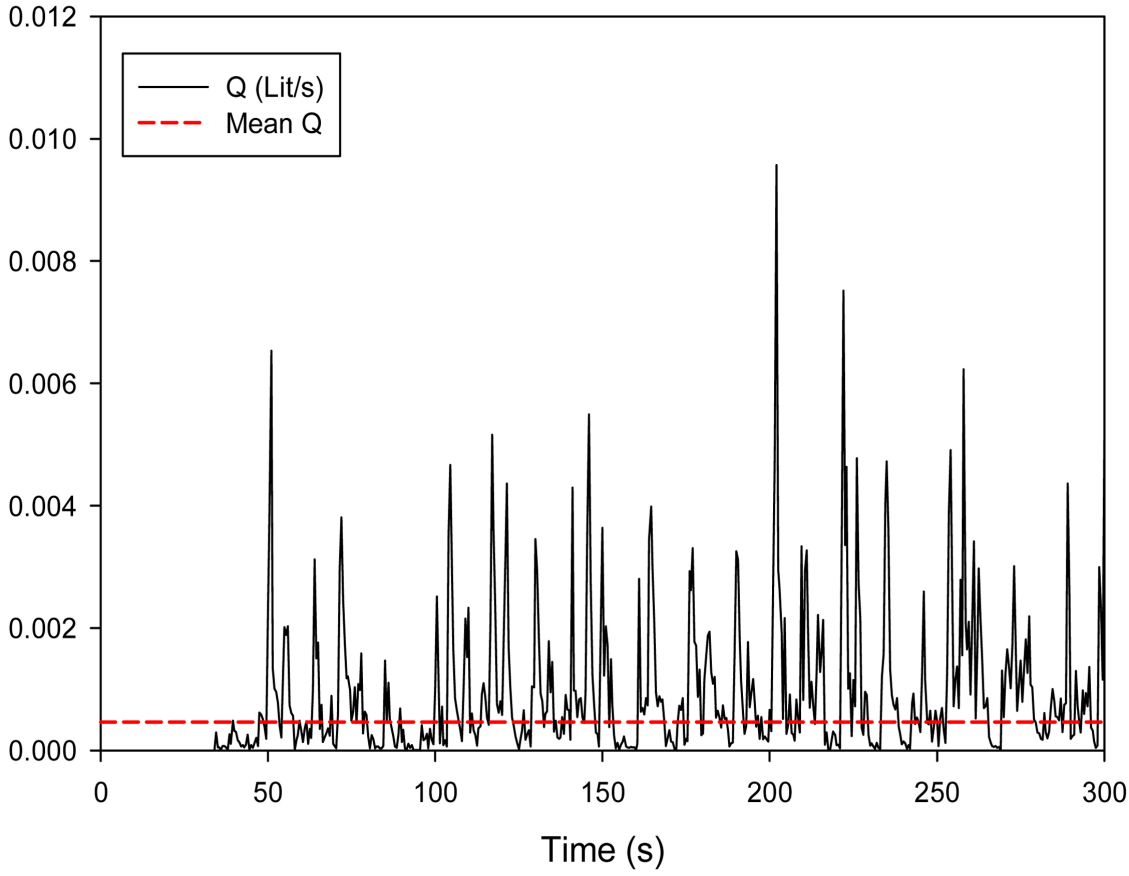

Figure 10. Output flow variation diagram in terms of time and average rate of discharge out of Armor breakwaters tetrapod blocks.

Table 3. The results of numerical model for relative wave height and wave velocity fluctuation parameters in Flow3D numerical model for different armor.

\begin{tabular}{ccccc}
\hline \multirow{2}{*}{ Run No. } & $\frac{R_{c}}{H_{m 0}}$ & $\frac{q}{\sqrt{g H_{m 0}^{3}}}$ & $\frac{R_{c}}{H_{m 0}}$ & $\frac{q}{\sqrt{g H_{m 0}^{3}}}$ \\
\cline { 2 - 5 } & \multicolumn{2}{c}{ Tetrapod Block } & \multicolumn{2}{c}{ Armour Xblock } \\
\hline Run No.1 & 0.77 & $5.83 \times 10^{-3}$ & 0.79 & $2.39 \times 10^{-2}$ \\
Run No.2 & 1.1 & $7.98 \times 10^{-4}$ & 1.06 & $1.87 \times 10^{-3}$ \\
Run No.3 & 1.17 & $2.14 \times 10^{-4}$ & 1.21 & $6.10 \times 10^{-4}$ \\
Run No.4 & 1.47 & $5.77 \times 10^{-5}$ & 1.58 & $6.77 \times 10^{-5}$ \\
Run No.5 & 1.62 & $5.72 \times 10^{-6}$ & 1.71 & $3.68 \times 10^{-5}$ \\
\hline
\end{tabular}




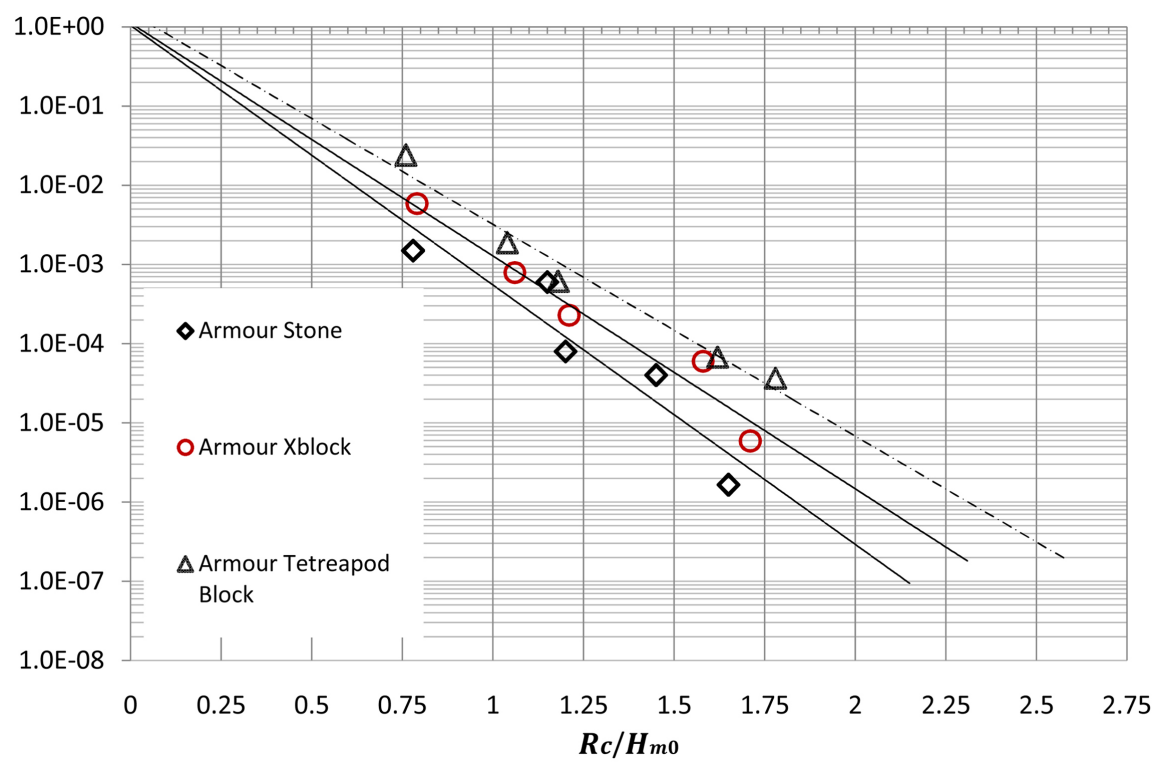

Figure 11. Results of numerical model for relative wave height parameters and wavelength overtopping in Flow3D numerical model for tetrapod armatures, $\mathrm{X}$ block.

\section{Conclusion}

The wave and its collision with the port and the coastal structures are always problematic, causing erosion of the port and coastal structures, and reduce the tourist attraction of some ports. To eliminate and reduce the phenomenon of wave overflow, a breakwater is used with various armor covers. One of the solutions is to increase the height of breakwaters in order to reduce further the phenomenon of wave propagation, which increases the cost of debris and increases cost. The optimal solution is to use reinforcements instead of increasing the height of the crushers to reduce and eliminate the transit phenomenon. Based on the results of numerical model, the maximum error of the numerical model for the relative height values of the collision waves to the crusher structure is maximum $7.87 \%$ for different conditions. Accordingly, the maximum error of the numerical model in determining the fluctuating discharge values as well as the laboratory conditions equal to $7.81 \%$. According to the results of numerical modeling, the X-block has a lower permeability than the tetrapod armor, so that the average flow rate of the $\mathrm{X}$-block reinforcements is about $31 \%$ less than the tetrapod armors in different conditions of the waves.

\section{References}

[1] Ebrahimi, A., et al. (2015) Investigation of Various Random Wave Run-up Amounts under the Influence of Different Slopes and Roughnesses. Environment Conservation Journal, 16, 301-308.

[2] Deilami-Tarifi, M., et al. (2016) Modeling of the Changes in Flow Velocity on Seawalls under Different Conditions Using FLOW-3D Software. Open Journal of Marine Science, 6, 317-322. https://doi.org/10.4236/ojms.2016.62026

[3] Deilami-Tarifi, M., et al. (2015) Effect of Slope, Size, and Arrangement of Roughness of Sea Wall on Overtopping of Random Waves. International Journal of Biol- 
ogy, Pharmacy And Applied Sciences, 4, 1026-1034.

[4] Rashidinasab, M. and Askar, M.B. (2017) Modeling the Pressure Distribution and the Changes of Water Level around the Offshore Platforms Exposed to Waves, Using the Numerical Model of Flow 3D. Computational Water, Energy, and Environmental Engineering, 6, 97-106. https://doi.org/10.4236/cweee.2017.61008

[5] van der Meer, J.W., Janssen, J.P.F.M. and Hydraulics, D. (1994) Wave Run-Up and Wave Overtopping at Dikes and Revetments. Delft Hydraulics, Delft.

[6] Owen, M.W. (1980) The Hydroulic Design of Seawall Profiles. Proceeding. Conference. on Shoreline Protection, London, 1980, 185-192.

[7] Hedges, T.S., Reis, M.T. and OWEN, M.W. (1998) Random Wave Overtopping of Simple Sea Walls: A New Regression Model. Proc. Ice-Water Marit. Energy, 130, $1-10$.

[8] Goda, Y. (2000) Random Seas and Design of Maritime Structures. University of Tokyo Press, Tokyo. https://doi.org/10.1142/3587

[9] Besley, P., Stewart, T. and Allsop, N.W.H. (1998) Overtopping of Vertical Structures: New Prediction Methods to Account for Shallow Waterconditions. The Institution of Civil Engineers, London, 46-57. https://doi.org/10.1680/csab.26681.0005

[10] Kobayashi, N. and Wurjanto, A. (1989) Wave Overtopping on Coastal Structures. Journal of Waterway, Port, Coastal, and Ocean Engineering, 115, 235-251. https://doi.org/10.1061/(ASCE)0733-950X(1989)115:2(235)

[11] Marayama and Hiraishi (1988) Presented a Numerical Model for Calculation of over Topping Discharge for a Vertical Breakwater in Multi Direction Wave, The Basic Assumption is that the Overtopping Discharge Can Be Described by a Weir Expression As suggested by Kikkawa et al. 1988.

[12] Bahadori, S. and Behdarvandi Askar, M. (2016) Investigating the Effect of Relative Width on Momentum Transfer between Main Channel and Floodplain in Rough Rectangular Compound Channel Sunder Varius Relative Depth Condition. Open Journal of Geology, 6, 225. https://doi.org/10.4236/ojg.2016.64020

[13] Ghatarband, M. and Behdarvandi Askar, M. (2016) Investigation of the Effect of the Circular Stands Diameters of Marine Structures and the Distances between Them on Wave Run-Up and Force. Marine Science, 6, 11-15.

[14] Bahadori, S. and Behdarvandi Askar, M. (2016) Investigating the Effect of Relative Depth and Relative Roughness on Momentum Transfer in Symmetric Rectangular Compound Channels with Varius Relative Width. International Journal of Hydraulic Engineering, 5, 1-8.

[15] Bruce, T., Van der Meer, J.W., Franco, L. and Pearson, J.M. (2008) Overtopping Performance of Different Armour Units for Rubble Mound Breakwaters. Coastal Engineering, 56, 166-179.

[16] Mifoor, I., et al. (2016) On the Investigation of Basic Parameters of Designing Protective Layer of the Offshore Breakwaters at Iran's Kharg Island. International Journal of Recent Scientific Research, 7, 9821-9823. 